\title{
Effects of Orchiectomy, Alone or in Combination with Testosterone, and Cyproterone Acetate on Exocrine Pancreatic Carcinogenesis in Rats and Hamsters
}

\author{
M. Meijers, ${ }^{1}$ C. J. T. Visser, ${ }^{1}$ J. G. M. Klijn, ${ }^{2}$ S. W. J. Lamberts, ${ }^{3}$ \\ A. van Garderen-Hoetmer, ${ }^{I}$ F. H. de Jong, ${ }^{4}$ J. A. Foekens, ${ }^{2}$ \\ and R. A. Woutersen ${ }^{*}$,
}

'Department of Biological Toxicology, TNO Toxicology and Nutrition Institute, Zeist, The Netherlands; ${ }^{2}$ Division of Endocrine Oncology (Department of Medical Oncology), Dr. Daniel den Hoed Cancer Center, 3008 AE Rotterdam, The Netherlands; ${ }^{3}$ Department of Internal Medicine, Erasmus University, Rotterdam, The Netherlands; and 'Department of Endocrinology and Reproduction, Erasmus University, Rotterdam, The Netherlands

\begin{abstract}
Summary
The results of a previous 4-mo study in azaserine-treated rats and BOP-treated hamsters indicated that orchiectomy inhibited pancreatic growth and development of putative preneoplastic lesions in the exocrine pancreas of rats but not hamsters. This 12-mo study was carried out to investigate the effects of orchiectomy, alone and in combination with testosterone, and of treatment with cyproterone acetate on pancreatic carcinogenesis in azaserine-treated rats and BOP-treated hamsters. Treatment started 4 mo after injection of the carcinogen. In orchiectomized rats, pancreatic wt was lower than in controls, whereas pancreatic wt of orchiectomized rats treated with testosterone was similar to that of controls. Both orchiectomy and cyproterone acetate caused a decrease in body wt gain and had an inhibitory effect on pancreatic carcinogenesis. Testosterone treatment did not influence the inhibitory effects of orchiectomy on body wt gain and on pancreatic carcinogenesis. In hamsters, neither orchiectomy, alone or in combination with testosterone, nor cyproterone acetate (CA) affected pancreatic growth or pancreatic carcinogenesis. This study indicates that testosterone plays a minor role in the development of pancreatic tumors induced in rats by azaserine but not in that of pancreatic tumors induced in hamsters by $B O P$.
\end{abstract}

Key Words: Exocrine pancreas; cancer; rat; hamster; orchiectomy; testosterone; cyproterone acetate.

\section{Introduction}

In most countries, the age-adjusted incidence of pancreatic cancer is higher in men than in women

Received (September 30, 1991); Revised (October 18, 1991); Accepted (November 12,1991)

*Author to whom all correspondence and reprint requests should be addressed at: Department of Biological Toxicology, TNO Toxicology and Nutrition Institute, PO Box 360, 3700 AJ Zeist, The Netherlands
$(1,2)$. Apart from life-style factors, hormonal factors have been suggested to be responsible for this sex difference. A higher number of atypical acinar cell nodules (AACN) and a higher incidence of pancreatic neoplasms have been found in male than in female rats treated with azaserine (3). Using the ATPase staining, Bax et al. found that acidophilic foci in male rats were consistently larger (1.75 times) than in females and concluded that the sex-related differ- 
ence in the numbers of acidophilic $A A C N$ induced in rat pancreas by azaserine may be ascribed to the difficulty in detecting small acidophilic foci in hematoxylin and eosin (H\&E)-stained sections (4). In rats, the inhibitory effect of castration on growth of azaserine-induced $A A C N$ has been ascribed to decreased serum testosterone levels $(5-7)$. The inhibitory effect of castration, however, was not influenced by treatment with testosterone. In a previous 4-mo study with azaserine-treated rats, we also found an inhibitory effect of orchiectomy on the development of AACN, which was accompanied by a significant decrease in absolute but not relative pancreatic wt. From the results of that study, we concluded that, apart from testosterone, nutritional status and pancreatic growth may play a highly significant role in the development of putative pancreatic preneoplastic lesions ( 8 ).

No consistent variations have been found in incidence of pancreatic (pre)neoplastic lesions in male and female hamsters induced by sc injections with nitrosamine derivatives. Pour et al. did not find a difference between male and female hamsters in the incidence of pancreatic tumors after injection with $N$-nitrosobis (2-oxopropyl)amine (BOP) $(9,10)$. Kokkinakis, on the contrary, found that tumor incidence, multiplicity, and size were generally larger in female than in male hamsters after administration of $N$-nitroso(2-hydroxypropyl)(2-oxopropyl)amine (HPOP) (11). Pancreatic (H2T) cells transplanted in hamster cheek pouches developed faster into ductal adenocarcinomas in intact females and castrated males than in ovariectomized females and intact males, respectively, pointing to an inhibitory effect of testosterone or an enhancing effect of estrogen (12). Schally and co-workers, however, found that the development of pancreatic tumors induced in male hamsters by BOP was inhibited by medical or surgical castration (13-18). Furthermore, in a previously conducted 4-mo study, we did not find any effect of castration or Luteinizing Hormone Releasing Hormone (LHRH) treatment on the development of early (pre)neoplastic lesions induced in hamster pancreas by BOP $(8)$. This experiment was performed to evaluate the effects of castration, either alone or in combination with testosterone treatment, and of treatment with the antiandrogen cyproterone acetate (CA) on pancreatic carcinogenesis in hamsters and rats during a long-term treatment period of 8 mo started $4 \mathrm{mo}$ after tumor induction.

\section{Materials and Methods}

\section{Animals and Tumor Induction}

Two hundred male weanling SPF albino Wistar Bor rats (WISW, Cpb) were obtained from F. Winkelmann (FRG) and injected ip four times with $30 \mathrm{mg}$ azaserine $/ \mathrm{kg}$ body wt at $19,26,33$, and $103 \mathrm{~d}$ of age. One hundred and forty male Syrian golden hamsters (Charles River Wiga, Sulzfeld, FRG) were each injected $\mathrm{sc}$, once weekly, with $20 \mathrm{mg} \mathrm{BOP} / \mathrm{kg}$ body wt at 6,7 , and 8 wk of age according to an injection protocol described previously (19). BOP (Ash Stevens, Inc., 5861 John C. Lodge Freeway, Detroit, MI 48202) and azaserine (CalbiochemBehring Corp., LaJolla, CA) were dissolved freshly in $0.9 \% \mathrm{NaCl}$ solution. The animals were allocated by a computerized randomization procedure to four different groups, each of which consisted of either 50 rats or 35 hamsters. The rats were housed in stainless-steel cages, fitted with wiremesh floors and fronts, and the hamsters in macrolon cages on softwood bedding. The animals were kept under standard laboratory conditions, five animals per cage, and fed a high fat/high protein diet during the first 4 mo of the study in order to enhance the development of ductular lesions in the exocrine pancreas.

\section{Treatment}

In order to mimic the human situation, treatment started when early (pre)neoplastic lesions had already developed in the pancreas, i.e. $4 \mathrm{mo}$ after the last injection with carcinogen. The animals received one of the following treatments: group A, saline (controls); group $B$, surgical castration; group $C$, surgical castration plus testosterone; and group D, CA. Testosterone was administered as testosterone proprionate by silastic implants as described previously (20). Rats received two, 3 -cm implants per animal, and hamsters, in view of lower body wt, received one implant per animal once at start of treatment. Cyproterone acetate was used as Androcur tablets (50 mg) dispersed in tap 
water. The animals were given $\mathrm{CA}$ by gavage daily at a dose of $50 \mathrm{mg} / \mathrm{kg}$, as described previously (2I).

During treatment, the animals were fed the TNO Institute's basal diet, which is low in fat $(5 \%)$ and compounded from natural feed ingredients. Body wt were recorded weekly during the first $3 \mathrm{mo}$ and once a month during the rest of the experiment. The general condition and behavior of the animals were checked daily.

\section{Autopsy and Histological Analysis}

In rats, an interim kill was performed on 20 animals of each group after 4 mo of treatment. Terminal autopsy on rats and hamsters was performed after 8 mo of treatment on days 371 (rats), and 363 and 364 (hamsters) after the last injection with carcinogen. The animals were anesthetized by ether, exsanguinated by cannulating the abdominal aorta, autopsied, and then examined for gross pathological changes. From each animal, the pancreas, liver, testes (if present), adrenals, and pituitary were excised and weighed. These organs were fixed in $10 \%$ buffered formalin. The pancreata were completely processed for microscopy by conventional methods, step-sectioned at $5 \mu \mathrm{m}$ (about 5 per pancreas), stained with $\mathrm{H} \& \mathrm{E}$, and examined by light microscopy. About $200 \mathrm{~mm}^{2}$ of pancreatic tissue of each rat were microscopically screened for the number and size of azaserine-induced AACN using a grid inside the ocular as described before (22). Only acidophilic AACN with transection areas greater than $0.5 \mathrm{~mm}^{2}$ have been counted and classified. $A A C N$, acinar cell adenomas $(A A C N$ with a transection area larger than $3 \mathrm{~mm}^{2}$ ), and (localized) carcinomas were identified and classified according to the criteria of Longnecker et al. $(3,23)$.

In the hamster pancreas, major attention was paid to tubular ductal complexes showing dysplasia or anaplastic changes, or desmoplasia, inflammation, with or without apoptosis, suggestive of progression to malignancy. Tubular ductal complexes exhibiting one or more of the characteristics were classified as "borderline lesions" (24). The ductular carcinomas induced by BOP were identified and classified according to Pour and Wilson (25).

Body and organ wt data were statistically evaluated with one-way analysis of variance (ANOVA) using initial body wt as covariable. The number of borderline and other (pre)neoplastic lesions were statistically evaluated with a generalized linear model (26). With such a model, the effects of type of treatment (control, surgical castration, surgical castration plus testosterone, or $\mathrm{CA}$ ) were assessed. For rats, the influence of time of sacrifice (interim kill, teminal autopsy) and possible interaction between type of treatment and time of sacrifice were assessed as well. A Poisson error distribution was used for evaluation of the lesions.

Evaluation of the prevalence (incidence) of tumors (terminal autopsy animals only) was done with a generalized linear model. The difference with the model used for lesions was the error distribution. With respect to prevalence, the binomial distribution was appropriate.

\section{Endocrine Investigations}

Blood sampling for hormone estimations was performed at the start of the treatment period $(n=19$ $20)$, after $4 \mathrm{mo}(n=10)$ and after $8 \mathrm{mo}(n=10)$ of treatment at the end of the experiment by exsanguination. In groups of five animals, blood sampling was also performed after 2 and 6 mo by orbita punctions. In Table 1, only the data obtained at 0,4 , and 8 mo after treatment have been included. EGFand IGF-1-like activities were measured in acid-ethanol extracted EDTA-plasmas by radioreceptor assays using human placental membrane preparations as receptor source. All procedures were exactly as described before for determination of EGF- and IGF1-like activities in human breast tumor cytosols (27). Growth hormone (GH) levels were determined by radioimmunoassay (RIA) (28). Testerone levels were estimated as described by Verjans et al. (29). The treatment effects on plasma hormone and growth factor levels were determined by ANOVA on the pooled data of all treatment groups and controls at the end of treatment. Small $p$ values from these analyses, performed for each growth factor or hormone in rats and hamsters, are an indication of a difference in effect, either a decrease or increase of plasma concentrations. In addition, to prevent the influence of outflyers, the Wilcoxon test has also been applied where useful. 
Tabie 1

Treatment Effects on Plasma Growth Factor and Hormone Levels

\begin{tabular}{|c|c|c|c|c|c|c|}
\hline \multirow{2}{*}{$\begin{array}{l}\text { Postinitiation } \\
\text { treatment group }\end{array}$} & \multicolumn{3}{|c|}{$\mathrm{GH}(\mathrm{ng} / \mathrm{mL})$} & \multicolumn{3}{|c|}{-Testosterone $(\mathrm{nmol} / \mathrm{L})$} \\
\hline & $0 \mathrm{Mo}$ & $4 \mathrm{Mo}$ & $8 \mathrm{Mo}$ & $0 \mathrm{Mo}$ & $4 \mathrm{Mo}$ & $8 \mathrm{Mo}$ \\
\hline \multicolumn{7}{|l|}{ Rats } \\
\hline Controls & $11.7 \pm 4.1^{b}$ & $2.4 \pm 0.8$ & $16.9 \pm 6.2(12)^{c}$ & $11.6 \pm 3.2$ & $2.7 \pm 0.5$ & $4.6 \pm 0.6(10)^{c}$ \\
\hline Castration & - & $5.7 \pm$ & $3.0 \pm 0.7(10)^{c}$ & - & $0.1 \pm 0.0$ & $0.1 \pm 0.0(10)^{c}$ \\
\hline Castration $+\mathrm{T}^{d}$ & - & $11.3 \pm$ & $20.8 \pm 9.1(10)^{c}$ & - & $16.9 \pm 1.2$ & $10.2 \pm 1.2(10)^{c}$ \\
\hline CPA & - & $24.5 \pm 14.4$ & $14.8 \pm 6.6(12)^{c}$ & - & $5.3 \pm 1.3$ & $11.6 \pm 3.1(12)^{c}$ \\
\hline$p$ value ${ }^{a}$ & & & $p=0.29$ & & & $p=0.0003$ \\
\hline \multicolumn{7}{|l|}{ Hamsters } \\
\hline Controls & $5.5 \pm 1.6$ & - & $2.8 \pm 0.7\left((12)^{c}\right.$ & $15.3 \pm 4.2$ & $6.3 \pm 0.8$ & $17.0 \pm 5.1(10)^{c}$ \\
\hline Castr & - & - & $4.3 \pm 0.6$ & - & & $0.1 \pm 0.0(10)^{c}$ \\
\hline Castration $+\mathrm{T}^{d}$ & - & - & $2.0 \pm 0.5(9)^{c}$ & - & $3.8 \pm 1.3$ & $2.2 \pm 0.5(10)^{c}$ \\
\hline $\begin{array}{l}\mathrm{CPA} \\
p \text { value }^{a}\end{array}$ & - & - & $\begin{aligned} 3.3 & \pm 0.5(12)^{c} \\
p & =0.09\end{aligned}$ & - & $10.8 \pm 1.5$ & $\begin{aligned} 13.0 & \pm 2.2(7)^{c} \\
p & =0.0000\end{aligned}$ \\
\hline \multirow{2}{*}{$\begin{array}{l}\text { Postinitiation } \\
\text { treatment group }\end{array}$} & \multicolumn{3}{|c|}{ EGF $(\mathrm{ng} / \mathrm{mL})$} & \multicolumn{3}{|c|}{ IGF (ng/mL) - } \\
\hline & 0 Mo & 4 Mo & $8 \mathrm{Mo}$ & 0 Mo & $4 \mathrm{Mo}$ & $8 \mathrm{Mo}$ \\
\hline \multicolumn{7}{|l|}{ Rats } \\
\hline Controls & $29.0 \pm 4.5$ & $53.4 \pm 6.3$ & $47.6 \pm 31.2(12)^{c}$ & $131 \pm 9$ & $200 \pm 11$ & $101 \pm 14(12)^{c}$ \\
\hline Castration & - & $68.2 \pm 8.7$ & $43.4 \pm 8.8(10)^{c}$ & - & $191 \pm$ & $94 \pm 11(10)^{c}$ \\
\hline Castration $+\mathrm{T}^{d}$ & - & $46.7 \pm 10.1$ & $31.0 \pm 5.1(9)^{c}$ & - & $161 \pm 19$ & $107 \pm 14(10)^{c}$ \\
\hline $\begin{array}{l}\text { CPA } \\
p \text { value }^{a}\end{array}$ & - & $15.2 \pm 6.5$ & $\begin{array}{c}45.2 \pm 28.7(12)^{c} \\
p=0.97\end{array}$ & - & $145 \pm 11$ & $\begin{array}{c}127 \pm 16(12)^{c} \\
p=0.35\end{array}$ \\
\hline \multicolumn{7}{|l|}{ Hamsters } \\
\hline Contr & $22.2 \pm 1.8$ & - & $62.8 \pm 4.5(12)^{c}$ & $255 \pm 14$ & - & $144 \pm 7(12)^{c}$ \\
\hline Castrat & - & - & $60.8 \pm 5.5(10)^{c}$ & - & - & $244 \pm 19(10)^{c}$ \\
\hline Castration + & - & - & $60.0 \pm 5.5(10)^{c}$ & _- & _- & $194 \pm 15(10)^{c}$ \\
\hline $\mathrm{CPA}$ & - & - & $76.5 \pm 5.6(13)^{c}$ & - & - & $206 \pm 18(13)^{c}$ \\
\hline$p$ value ${ }^{a}$ & & & $p=0.09$ & & & $p=0.0005$ \\
\hline
\end{tabular}

${ }^{a} P$ value associated with test of difference between the five groups after 8 mo of treatment. ${ }^{b}$ All values are means \pm SEM. ${ }^{c}$ Number of animals used at 8 mo between brackets; at start of trearment 19-20 animals, and after 4 mo 10 animals were used for assays. ${ }^{\mathrm{d}} \mathrm{T}=$ testosterone.

\section{Results}

\section{Body Weights}

In rats but not hamsters, orchiectomy inhibited body growth by $19 \%(p<0.01)$ (Figs. 1,2; Tables 2,3). Body wt of orchiectomized rats treated with testosterone was also significantly lower (15\%) than that of controls. Rats treated with CA also showed a lower body wt $(p<0.01)$ than controls, whereas body wt of hamsters treated with CA had increased by $10 \%(p<0.05)$ compared to controls.

\section{Organ Weights}

In rats, absolute but not relative pancreas wt had decreased $(p<0.01)$ by orchiectomy and by treatment with CA $(p<0.05)$, when compared with controls (Table 2). Suppletion with testosterone restored greatly the loss of absolute pancreas wt caused by orchiectomy, resulting in the absence of a significant difference with the control group.

In orchiectomized rats, absolute and relative pituitary wt increased $(p<0.01)$. Suppletion with testosterone prevented the absolute increase but not the 


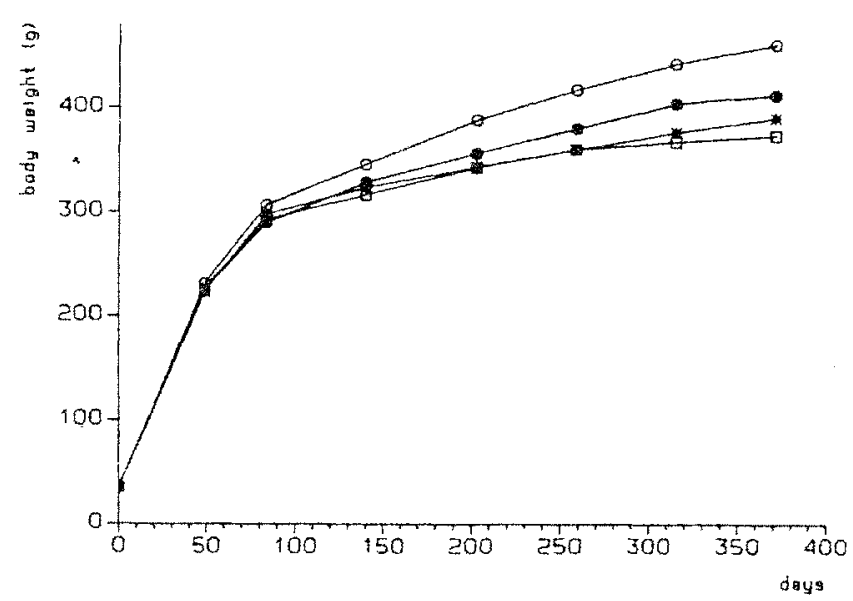

Fig. 1. Mean body wt in rats. $O=$ control; $\square=$ castration; $*$ castration + testosterone; and $\bullet=\mathrm{CA}$.

relative increase in pituitary wt. Adrenal wt was not significantly affected by any of the treatment modalities.

In rats, absolute liver wt was lower $(p<0.01)$ in all treated groups, whereas relative liver wt was only lower in orchiectomized rats not treated with testosterone $(p<0.01)$. In hamsters, apart from an increase of pituitary wt by castration, none of the treatments significantly influenced absolute or relative organ wt (Table 3).

\section{Plasma Growth Factor and Hormone Levels}

In rats, significant differences among groups were observed at the end of the experiment with respect to EGF- and IGF-1-like activity and plasma GH levels (Table 1). Plasma IGF-1 levels increased until 4 mo of treatment and subsequently decreased to adult values when the growth curves were (nearly) flattened. Plasma GH levels tended to decrease after surgical castration and to increase in case of testosterone substitution, but the differences were not significant compared to controls (by ANOVA and Wilcoxontest analyses). During the treatment period, plasmatestosterone concentrations were lower than before in the control group, maybe as a consequence of late damage of testicular function by carcinogens. As expected, surgical castration caused very low plasma testosterone levels. Substitution with testosterone implants caused significant plasma testosterone concentrations comparable with those present in the con-

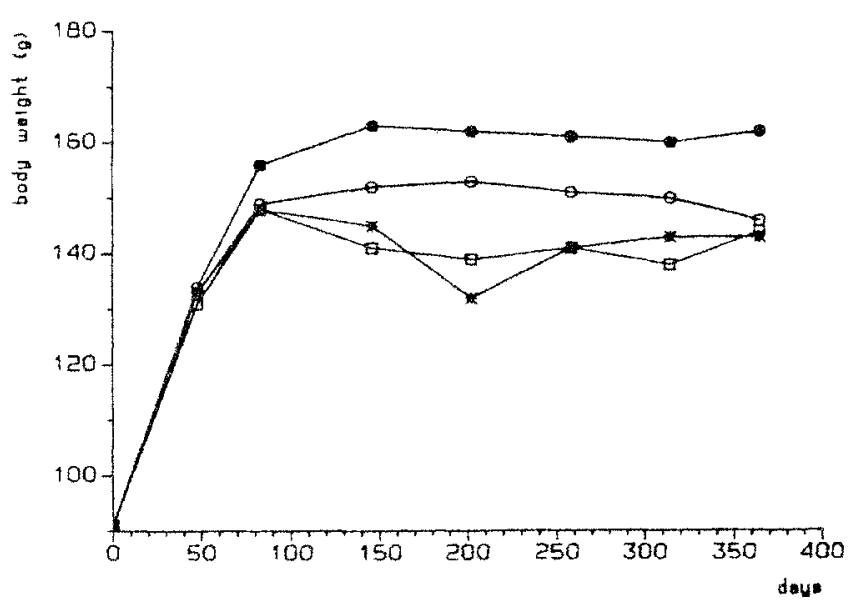

Fig. 2. Mean body wt in hamsters. $O=$ Control; $\square=$ castration; $=$ castration + testerone; and $=\mathrm{CA}$.

trol group before treatment. Cyproterone acetate did not decrease plasma testosterone, as could be expected.

In hamsters, no differences were found among groups with respect to EGF-like activity, whereas IGF1 levels were higher in the treatment groups compared with those of controls (all $p<0.01$, Wilcoxon test). Although plasma $\mathrm{GH}$ tended to be higher in castrated animals, overall there were no clear differences among groups. As expected, after castration, plasma testosterone levels were very low. Testosterone substitution caused significant plasma testosterone concentrations, but lower than in rats possibly as a consequence of the lower dose used.

\section{Microscopy}

In rats, multiplicity of lesions increased significantly in time (Table 4). After 8 mo of treatment, the number of $\mathrm{AACN}$ with transection areas larger than $0.5 \mathrm{~mm}^{2}$ was lower $(p<0.01)$ in each of the treatment groups in comparison with controls. The number of adenomas was similar in all groups, controls included. The total number (multiplicity) but not the incidence (Table 6) of carcinomas was lower $(p<0.05)$ in all treatment groups after 8 mo of treatment (Table 4).

In hamsters, none of the treatments had a significant effect on either the number of borderline lesions, the multiplicity or the incidence of carcinomas (Tables $5,6)$. Surgical castration decreased the number and the incidence of total carcinomas with about $50 \%$, but this difference did not appear to be statistically significant. 


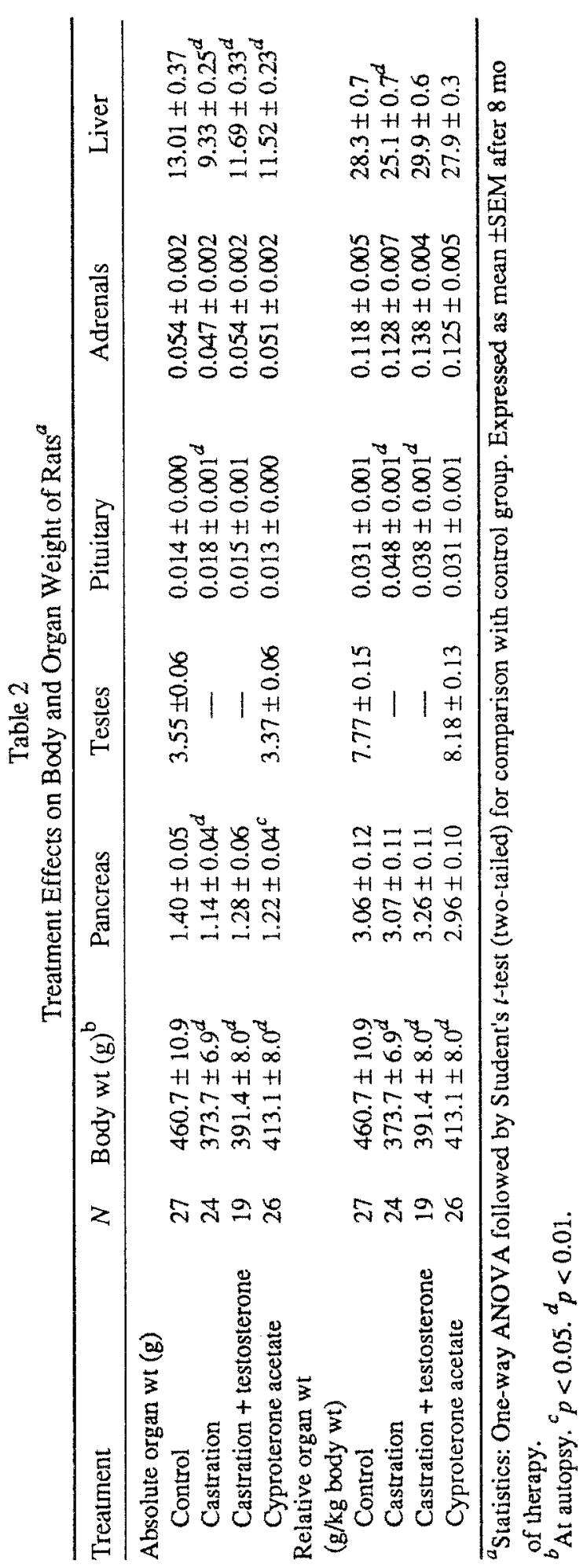

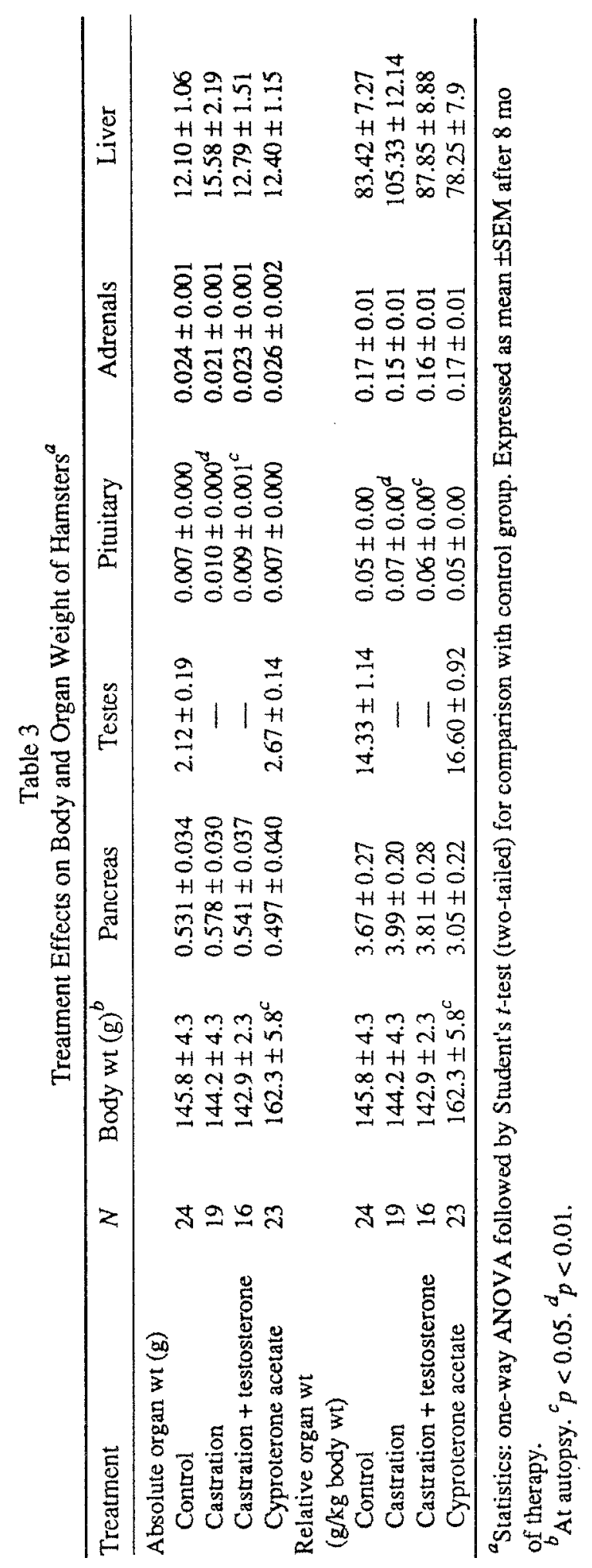




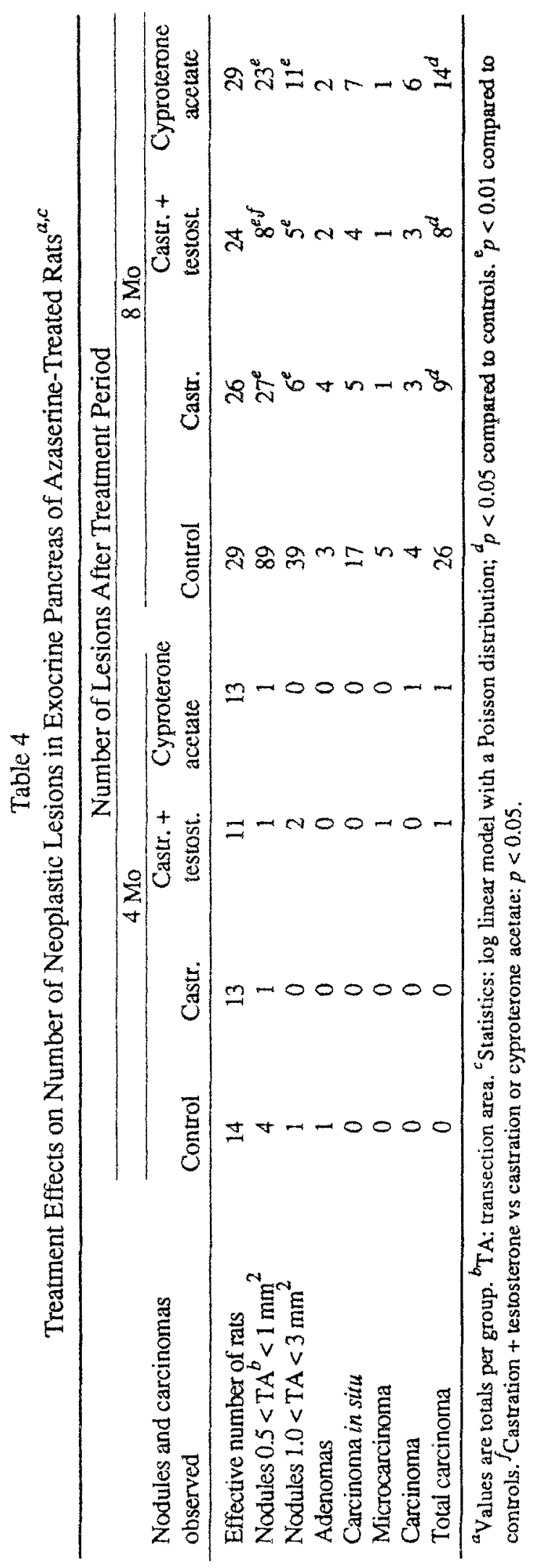


Table 5

Treatment Effects on Number of (Pre)neoplastic Lesions in Exocrine Pancreas of BOP-Treated Hamsters ${ }^{a, b}$

\begin{tabular}{lcccc}
\hline & \multicolumn{5}{c}{ Number of lesions } \\
\cline { 2 - 5 } $\begin{array}{l}\text { Advanced Ductular } \\
\text { Lesions Observed }\end{array}$ & Control & Castration & $\begin{array}{c}\text { Castration }+ \\
\text { testosterone }\end{array}$ & $\begin{array}{c}\text { Cyproterone } \\
\text { acetate }\end{array}$ \\
\hline $\begin{array}{l}\text { Effective number } \\
\text { of animals }\end{array}$ & 26 & 26 & 26 & 28 \\
Borderline lesion & 227 & 214 & 204 & 221 \\
Carcinoma in situ & 5 & 0 & 0 & 2 \\
Microcarcinoma & 5 & 1 & 3 & 0 \\
Carcinoma & 5 & 6 & 8 & 11 \\
Total carcinoma & 15 & 7 & 11 & 13 \\
\hline${ }^{a}$ Values are totals per group. ${ }^{b}$ Statistics: log-linear model with a Poisson error distribution. There were no \\
significant differences between the treatments.
\end{tabular}

Table 6

Treatment Effects on Incidence of Carcinomas

in Exocrine Pancreas of Azaserine-Treated Rats and BOP-Treated Hamsters

\begin{tabular}{|c|c|c|c|c|}
\hline \multirow[b]{2}{*}{ Neoplastic lesion observed } & \multicolumn{4}{|c|}{ Number of lesions } \\
\hline & Control & Castration & $\begin{array}{l}\text { Castration + } \\
\text { testosterone }\end{array}$ & $\begin{array}{l}\text { Cyproterone } \\
\text { acetate }\end{array}$ \\
\hline \multicolumn{5}{|l|}{ Incidence of pancreatic carcinomas in rats ${ }^{a}$} \\
\hline Effective number of animals & 29 & 26 & 24 & 29 \\
\hline Number of animals bearing a lesion & 11 & 6 & 7 & 13 \\
\hline \multicolumn{5}{|c|}{ Incidence of pancreatic carcinomas in hamsters ${ }^{b}$} \\
\hline Effective number of animals & 26 & 26 & 26 & 28 \\
\hline Number of animals bearing a lesion & 14 & 7 & 10 & 10 \\
\hline
\end{tabular}

${ }^{a}$ Statistics: generalized linear model with a binomial error distribution. ${ }^{b}$ Statistics: generalized linear model with a binomial error distribution. There were no significant differences between the treatments.

\section{Discussion}

The results of the present 12 -mo study indicate that orchiectomy and treatment with CA cause a decrease in body wt gain and absolute pancreatic wt in rats but not hamsters and inhibition of pancreatic carcinogenesis in azaserine-treated rats but not BOP-treated hamsters. Moreover, treatment of orchiecto-mized rats with testosterone did not affect the inhibitory effect of surgical castration on body wt gain in spite of the presence of normal plasma testosterone levels, whereas pancreas wt of testosterone-treated castrated rats had increased in comparison to orchiectomized rats not treated with testosterone.
The conclusion that testosterone has an enhancing effect on pancreatic carcinogenesis in azaserinetreated rats has been based on the observation that orchiectomy and estradiol treatment inhibited the development of $\mathrm{AACN}(6,7)$. In a previously performed 4-mo study with azaserine-treated rats (8), we also found that orchiectomy reduced the yield of AACN significantly, but this effect was accompanied by a significant decrease in growth of absolute pancreatic wt. After correction for pancreas wt, the number of $\mathrm{AACN}$ in the orchiectomized rats was almost similar to that in intact controls $(8)$.

Based on these findings, we concluded that a substantial decrease in body growth rate as observed in 
surgically castrated rats has to be considered a confounding factor in such experiments, which, if not taken into account, may have led to an overestimation of the direct, enhancing effect of testosterone on pancreatic carcinogenesis.

The results of this study support this conclusion, since it appears that castrated rats treated with testosterone develop even less AACN in comparison with castrated rats not treated with testosterone (Table 4). Treatment of orchiectomized rats with testosterone did not result in a tumor yield similar to that of intact controls, notwithstanding the fact that pancreatic wt in the testosterone-treated group was almost similar to that of controls. This observation indicates that changes in body wt during different treatment modalities are at least as important as changes in plasma-testosterone concentrations. On the other hand, the level of plasma testosterone concentrations might be of importance, i.e., high and castration levels, inhibitory and intermediate levels, stimulatory. In agreement with this hypothesis are the findings of Greenway and colleagues (30), showing low but not castration levels of testosterone in patients with carcinoma of the pancreas. Furthermore, relative loss of body wt might decrease (intratumoral) aromatase activity, resulting in a decreased conversion of androgens to estrogens.

The findings in hamsters are in agreement with those in our previous 4-mo study ( 8 ). In BOP-treated hamsters, orchiectomy did not influence body wt gain, and only slightly but not significantly inhibited pancreatic carcinogenesis. The present findings support partly those of Zalatnai and Schally $(13-18)$ who found a significant decrease in tumor wt and tumor volume but no effect on the incidence of ductular adenocarcinomas in chemically (LHRH-treated) castrated (BOP-treated) hamsters.

Based on the aforementioned findings, it might be possible that early putative preneoplastic acinar and ductular lesions, which develop in the pancreas of rats and hamsters after treatment with azaserine and BOP, respectively, do not contain steroid receptors and, hence, cannot be modulated by testosterone. It may be concluded, therefore, that manipulation of pancreatic carcinogenesis by steroid hormones is only relevant for the treatment of existing carcinomas.
Based on the findings described in this article, it may be concluded that the observed inhibitory effects of orchiectomy and cyproterone acetate on pancreatic carcinogenesis in azaserine-treated rats may, at least partly, be ascribed to a significant decrease in body growth. However, the mechanism of action of relative delay in body growth on pancreatic carcinogenesis is still unclear. Importantly, we did not observe a significant decrease in $\mathrm{GH}$ and growth factor secretion, or in our previous study in gastrin secretion (8). Therefore, studies on the effect of relative wt loss on other factors potentially involved in pancreatic carcinogenesis are needed.

\section{Acknowledgments}

This study is supported by grant CIVo 87-01 of the Dutch Cancer Society. We would like to thank Organon, Oss, The Netherlands for the supply of testosterone and Schering, Berlin, FRG, for the supply of $\mathrm{CA}$.

We also wish to thank A. A. van Tuyl and $M$. Stoepker for technical assistance, as well as J. M. Klokman-Houweling, E. Schoen, and H. Portengen for their help with respect to statistical evaluation of the data. We are grateful to V. J. Feron and R. J. J. Hermus for evaluation of the manuscript.

\section{References}

1 Levin DL, Connelly RR, and Deveja SS. Demographic characteristics of cancer of the pancreas: mortality, incidence and survival. Cancer 1981; 47: 1456-1468.

2 Czernichow P, Lerebours E, and Colin R. Epidémiologie du cancer du pancreas. Donnees actuelles. Presse Méd 1986; 15: 387-391.

3 Longnecker DS. The azaserine-induced model of pancreatic carcinogenesis in rats. Experimental Pancreatic Carcinogenesis, Scarpelli DG, Reddy JK, Longnecker DS, eds., CRC, Boca Raton, FL, 1987; 117-157.

4 Bax J, Schippers-Gillissen C, Woutersen RA, and Scherer E. Kinetics of induction and growth of putative precancerous acinar cell foci in azaserine-induced rat pancreas carcinogenesis. Carcinogenesis 1990; 11: 245-250.

5 Hayashi $Y$ and Takahashi $M$. Modulation of pancreatic acinar cell carcinogenesis by testosterone. Experimental Pancreatic Carcinogenesis, Scarpelli DG, Reddy JK, Longnecker DS, eds., CRC, Boca Raton, FL, 1987; 199-206.

6 Lhoste EF, Roebuck BD, Brinck-Johnson T, and Longnecker DS. Effect of castration and hormone replace- 
ment on azaserine-induced pancreatic carcinogenesis in male and fernale Fischer tats. Carcinogenesis 1987; 5: 699703.

7 Sumi C, Longnecker DS, Roebuck BD, and Brinck-Johnson $T$. Inhibitory effects of estrogen and castration on the early stage of pancreatic carcinogenesis in Fischer rats treated with azaserine. Cancer Res 1989; 49: 2332-2336.

8 Meijers M, Woutersen RA, van Garderen-Hoetmer A, Bakker GH, de Jong FH, Foekens JA, and Klijn JGM. Effects of castration, alone and in combination with aminoglutethimide, on grow th of (pre)neoplastic lesions in exocrine pancreas of rats and hamsters. Carcinogenesis 1991; 12: 1707-1713.

9 Pour P, Althoff J, Krüger FW, and Mohr U. A potent pancreatic carcinogen in Syrian hamsters: $N$-nitrosobis(2oxopropy)amine. J Natl Cancer Inst 1977; 58: 1449-1453.

10 Pour P, Wallcave L, Gingell R, Nagel D, Lawson T, Salmasi $\mathrm{S}$, and Tines $\mathrm{S}$. Carcinogenic effect of $\mathrm{N}$-nitroso(2hydroxopropyl)(2-oxopropyl)amine, a postulated proximate pancreatic carcinogen in Syrian hamsters. Cancer Res 1979; 39: 3828-3833.

11 Kokkinakis DM. Sex differences in the dietary modulation of pancreatic cancer in Syrian hamsters treated continuously with $N$-nitroso(2-hydroxypropyl)(2-oxopropyl)amine. Carcinogenesis 1990; 11: 1909-1913.

12 Evers BM, Singh P, Townsend CM Jr., Glass E, and Thompson JC. Sex differences in growth of pancreatic cancer. Pancreas 1989; 4: 615, abstract.

13 Redding TW and Schally AV. Inhibition of growth of pancreatic carcinomas in animal models by analogs of hypothalamic homones. Proc Natl Acad Sci USA 1984; 81: 248-252.

14 Paz-Bouza II, Redding TW, and Schally AV. Treatment of nitrosamine-induced pancreatic tumors in hamsters with analogs of somatostatin and luteinizing hormone-releasing hormone. Prac Natl Acad Sci USA 1987; 84: 1112-1116.

15 Zalatnai A and Schally AV. Responsiveness of the hamster pancreatic cancer to treatment with microcapsules of $\mathrm{D}-\mathrm{T}$ Tp6-LH-RH and somatostatin analog RC-160. Int J Pancreat 1989; 4: 149-160.

16 Zalatnai A and Schally AV. Treatment of BOP-induced pancreatic cancer in Syrian golden hamsters with D-Trp-6LH-RH and somatostatin analogue RC-160 microcapsules. Cancer Res 1989; 49: 1810-1815.

17 Szende B, Zalatnai A, and Schally AV. Programmed cell death (apoptosis) in pancreatic cancers of hamsters after treatment with analogs of both luteinizing hormonereleasing hormone and somatostatin. Proc Natl Acad Sci USA 1989; 86: 1643-1647.

18 Szende B, Srkalovic G, Groot K, Lapis K, and Schally AV. Regression of nitrosamine-induced pancreatic cancers in hamsters treated with luteinizing hormone-releasing hormone antagonists or agonists. Cancer Res 1990; 50: $3716-3721$.

19 Woutersen RA, van Garderen-Hoetmer A, and Longnecker DS. Characterization of a 4-month protocol for the quantitation of BOP-induced lesions in hamster pancreas and its application in studying the effects of dietary fat. Carcinogenesis 1987; 8: 833-837.

20 Bosland MC, Scherrenberg PM, de Bie BTHJ, and Dreefvan der Meulen H. C. Promotion of N-Methyl-NNitrosourea-induced prostatic carcinogenesis by testosterone: preliminary observations, Thesis by M.C. Bosland, Prostatic Carcinogenesis, Utrecht, 1989: 277-285.

21 Bosland MC, Weisburger JH, Rivenson A, Silverman J, Williams GM, and Kroes R. Comparison of induction of tumors of the prostate and other tissues in male Fischer F344, Sprague Dawley, and Wistar rats by $N$-Methyl-NNitrosourea after sequential treatment with cyproterone acetate and testosterone propionate, Thesis by M.C. Bosland, Prostatic Carcinogenesis, Utrecht 1989: 221-239.

22 Woutersen RA, van Garderen-Hoetmer A, Bax J, Feringa AW, and Scherer E. Modulation of putative preneoplastic foci in exocrine pancreas of rats and hamsters: interaction of dietary fat and ethanol. Carcinogenesis 1986; 7: 1587-1593.

23 Longnecker DS, Pettengill OS, Davis BH, Schaeffer BK, Zurlo J, Hong HL, and Kuhlmann ET. Characterization of preneoplastic and neoplastic lesions in the rat pancreas. $A m$ J Pathol 1991; 138: 333-340.

24 Meijers M, van Garderen-Hoetmer A, Lamers CBHW, Rovati LC, Jansen JBMJ, and Woutersen RA. Role of cholecystokinin on the development of BOP-induced pancreatic lesions in hamsters. Carcinogenesis 1990; 11 : 2223-2226.

25 Pour PM and Wilson RB. Experimental pancreas tumors. Moossa AR, ed., Tumors of the Pancreas, Williams and Wilkins, Baltimore, 1980, 37-158.

26 McCullagh $P$ and Nelder JA. Generalized Linear Models, Chapman \& Hall, New York, 1989.

27 Foekens JA, Portengen H, Janssen M, and Klijn JGM. Insulin-like growth factor-1 receptors and insulin-like growth factor-1-like activity in human primary breast cancer. Cancer 1989; 63: 2139-2141.

28 Lamberts SWJ, Reubi JC, Uitterlinden P, Zuiderwijk J, van der Werff P, and yan Hal P. Studies on the mechanism of action of the inhibitory effect of somatostatin analog SMS 201-995 on the growth of the prolactin/adrenocorticotropinsecreting pituitary tumor 7315 a. Endocrinology $1986 ; 118$ : 2188-2194.

29 Verjans HL, Cooke BA, de Jong FH, de Jong CMA, and $v$ an der Molen HJ. Evaluation of a radioimmunoassay for testosterone estimation. J Steroid Biochem 1974; 4: 665-676.

30 Greenway B, Iqbal MJ, Johnson PJ, and Williams R. Low serum testosterone concentrations in patients with carcinoma of the pancreas. Br Med $J$ 1983; 286: 93-95. 